$2-2006$

\title{
Mortality of the Oldest Old in China
}

\author{
Rongjun Sun \\ Cleveland State University, r.sun32@csuohio.edu \\ Yuzhi Liu \\ Peking University, Peking
}

Follow this and additional works at: https://engagedscholarship.csuohio.edu/clsoc_crim_facpub

Part of the Demography, Population, and Ecology Commons

How does access to this work benefit you? Let us know!

Publisher's Statement

(c) 2006 SAGE Publications

\section{Original Citation}

Sun, R., , \& Liu, Y. (2006). Mortality of the Oldest Old in China. Journal of Aging and Health, 18(1), 37-55.

\section{Repository Citation}

Sun, Rongjun and Liu, Yuzhi, "Mortality of the Oldest Old in China" (2006). Sociology \& Criminology Faculty Publications. 21.

https://engagedscholarship.csuohio.edu/clsoc_crim_facpub/21

This Article is brought to you for free and open access by the Sociology \& Criminology Department at EngagedScholarship@CSU. It has been accepted for inclusion in Sociology \& Criminology Faculty Publications by an authorized administrator of EngagedScholarship@CSU. For more information, please contact library.es@csuohio.edu. 


\title{
MORTALITY OF THE \\ OLDEST OLD IN OHINA: \\ THE ROLE OF SOOIAL \\ AND SOLITARY \\ OUSTOMARY \\ ACTIVITIES
}

\author{
Rongjum Sum, Cleveland State \\ University, Cleveland \\ Yuzhi Inim, Peking University, \\ Peking, China
}

\begin{abstract}
Objective: This study investigates the role of customary activities, both social and solitary, in mortality among the oldest old in China. Methods: The data come from the Chinese Longitudinal Healthy Longevity Survey. Weibull hazard models analyze the mortality risk of those 80 years of age and older within a 2 -year petiod between 1998 and 2000. Results: Results show that solitary activities, either active or sedentary, are significantly associated with lower mortality risk. The effect of social activities on mottality gradually diminishes with age and is reversed at very old ages when physical exercise, health status, and sociodemographic characteristics are controlled. Discussion: Customary activities, which are less physically demanding, show independent effects on the elderly's survival. Withdrawal from social contacts may be an adaptive response to challenges faced at very advanced ages. It is important to tecognize the unique characteristics of this rapidly growing population.
\end{abstract}

Keywords: oldest old; customary activities, mortality; China

As predicted by the United Nations (2001), the proportion of those 80 years of age and older will increase from about $1 \%$ in 2000 to more than $4 \%$ in 2050 . This age group is the fastest growing cohort of any other groups in the older population (Suzman, Manton, \& Willis, 1992). Population aging is not just experienced by the more developed countries; it has become visible in much of the developing world as

AUTHORS' NOTE: We thank Dr. Sarah Matthews and the two anonymous reviewers for their comments and suggestions. Address correspondence to Rongiun Sun, Department of Sociology Cleveland State University, 2121 Euclid Ave, Cleveland, OH 44115, e-mail: r.sun32@ csuohio.edu. 
well. Whereas $53 \%$ of people 80 years of age and older lived in more developed regions in the year $2000,57 \%$ is expected to live in less developed regions by the year 2025 , with an expected increase to $70 \%$ by the year 2050 . In 2000 , China, the world's most populous nation, already had the largest number of people 80 years of age and older (12 million) in the world (United Nations, 2001). Furthermore, this age group is predicted to expand at a $4.4 \%$ annual rate, the highest among all age groups of the elderly population aged 65 and above (Zeng \& Vaupe1, 2002). Although there have been studies of mortality of the elderly in China (Anderson, Kim, Romani, Traphagan, \& Liu, 1999; Ho, 1991; Liang et al, 2000; Liu, Hermalin, \& Chuang, 1998; Yu et al., 1998), none focused exclusively on the oldest old - those who are 80 years of age and older.

\section{Research Objectives}

As shown in the literature, physical and cognitive status (Anstey, Luszcz, \& Giles, 2001; Liang et al., 2000; Parker, Thorslund, \& Nordstrom, 1992), health behaviors (Berkman, Breslow, \& Wingard, 1983; Kaplan, Seeman, Cohen, Knudsen, \& Guralnik, 1987), and sociodemographic characteristics (Kaplan, 1992; Kaplan, Hann, Syme, Minkler, \& Windeby, 1987) all have impacts on mortality. This study focuses on the role of customary activities in the survival of Chinese elderly 80 years of age and older during a 2 -year time period.

Although the value of engaging in physical activities for all aspects of well-being is well established in the literature (Belloc, 1973; Berkman et al., 1983; Cerhan et al., 1998; Rowe \& Kahn, 1998), increasing attention is being paid to customary, or habitual, activities. These are less physically demanding relative to fitness exercise but have distinctive effects on the elderly's well-being and survival (Bygren, Konlann, \& Johansson, 1996; DiPietro, 2001; Glass, Mendes de Leon, Marottoli, \& Berkman, 1999; Lennartsson \& Silverstein, 2001; K. Morgan \& Clarke, 1997; K. Morgan etal., 1991; Welin, Larsson, Svardsudd, Tibblin, \& Tibblin, 1992). For instance, some home activities, including gardening, repairing, and reading, were found to be associated with lower level of mortality in a 12-year study of Swedish men bom in 1913 and 1923 (Welin et al., 1992). In 
addition, investigators tend to differentiate among customary activities. Glass and colleagues (1999), for example, categorized church attendance and participation in social groups as social activities and gardening and preparing meals as productive activities. Lennartsson and Silverstein (2001) developed a two-dimension frameworksocial versus solitary and active versus sedentary-and used it to define four distinct types of activities: social-friendship activities (e.g., visiting friends), social-cultural activities (e.g., going to movies and eating at restaurants), solitary-active activities (e.g., gardening and engaging in hobbies), and solitary-sedentary activities (e.g., reading and solving puzzles).

There seems to be a strong consensus regarding the effect of solitary activities, especially solitary-active activities, in the literature. A longitudinal survival analysis of people aged 65 and older in the United States showed that engaging in gardening, preparing meals, and shopping were associated with lower hazard of death even after the effect of physical fitness was controlled (Glass et al., 1999). A similar study also demonstrated a clear relationship between customary activities (including housework, walking, shopping, etc.) and 10-year mortality (K. Morgan \& Clarke, 1997). The beneficial effects on survival of gardening and engaging in hobbies were also evident in a Swedish sample of people aged 77 and above (Lennartsson \& Silverstein, 2001). The benefits of such activities are proposed to be mediated through an array of physiological and psychosocial pathways, such as maintenance of normal mental state, distraction from negative memories, a sense of self-mastery, and a sense of meaning and purpose in life (Glass et al., 1999; K. Morgan et al, 1991).

In contrast, the role of social activities is less conclusive. Past research has demonstrated that social integration and social engagement in general have a positive impact on the elderly's physical health, mental health, and survival (Berkman \& Breslow, 1983; Berkman, Glass, Brissete, \& Seeman, 2000; Sabin, 1993; Zunzunegui, Alvarado, Ser, \& Otero, 2003). Relating to others is usually seen as essential to well-being, whereas lack of social ties is viewed as a risk factor (Rowe \& Kahn, 1998). Disengagement theory, however, states that normal aging involves inevitable withdrawal from social ties to prevent disruption to the social system (Cumming \& Henry, 1961). Although it has been controversial, some studies have shown the rele- 
vance of this theory for the oldest old population. Johnson and Barer (1992) reported in their study of people aged 85 or above in San Francisco that less than $10 \%$ of their sample had weekly contact with siblings, and less than $30 \%$ had weekly contact with other relatives. Intensive interviews revealed that these elderly disengaged socially and psychologically by narrowing their social boundaries, loosening normative constraints, shifting their time orientation from the future to the present, and increasing introspection. Using the General Social Survey, D. L. Morgan (1988) documented a downward trend in social network participation by age among those aged 60 and above even after available resources, such as income, education, and health were controlled. Older respondents maintained fewer roles than younger respondents did. They named fewer people with whom they discussed important matters or were in frequent contact and relied more on family members and long-time relationships. Lang and Carstensen's (1994) study showed that among Berlin residents aged 70 to 104 years, there was a significant negative correlation between social network size and age. The very old tended to limit social contacts to very intimate and close ties. They found a dramatic reduction in contacts with more distant social partners. These findings were interpreted by a socioemotional selectivity theory (Carstensen, 1991, 1992), which takes a life span perspective that "views reductions in social activity in old age as reflective of the culmination of selection processes that begin early in life and have substantial adaptive value" (Carstensen, 1991, p. 195). According to this theory, in old ages, people selectively invest increasingly limited resources in the most valuable and intimate relationships and disregard less important ones. Selectivity is an adaptive strategy to yield the greatest gain in well-being.

Although social activities were found to be beneficial in the Glass and colleagues (1999) study, studies that directly tested the relationship between social contacts and mortality have not evaluated how that effect changed by age. In a 10-year longitudinal study of the elderly aged 60 or above in Taiwan, Cornman, Goldman, Glei, Weinstein, and Chang (2003) did not find any significant impact of the number of friends or the number of social activities on the probability of dying when controlling for prior health. The effect of social contacts on mortality also was found to be insignificant in a sample of Australian 
elderly aged 70 or above (Korten et al., 1999) and a sample of Swedish elderly 77 or older (Lennartsson \& Silverstein, 2001).

There is a paucity of research examining customary activities among the oldest old in non-Western social settings. Whether the relationship between social contacts and mortality changes by age has not been tested with large-scale data. The research objectives for this investigation are the following: First, we examine whether solitary activities (activities participated in by the respondent alone, without the involvement of others), both active (which involve physical mobility) and sedentary (which do not involve much physical mobility), have any positive effect on the survival of the oldest old Chinese even after physical exercise and other characteristics are taken into account. Second, we examine whether the favorable effect of social contacts on survival gradually diminished with age or, in other words, whether reductions in social contacts were associated with lower level of mortality in very old ages.

\section{Data and Method}

\section{SAMPLE}

This study used the Chinese Longitudinal Healthy Longevity Survey (CLHLS), which was jointly conducted by the Institute of Population Research at Peking University, China Research Center on Aging, and Duke University. The CLHLS is a national, longitudinal survey of the oldest Chinese elderly who were defined as being 80 years of age and older. It collects information on sociodemographic characteristics, cognitive and physical health status, and lifestyle. It covers 22 of the 29 provinces, constituting $85 \%$ of the total population. It adopted a combination of a stratified and random sampling design, covering both urban and rural areas. The first round of the survey was conducted in 1998, collecting a total of 9,073 valid questionnaires with a response rate of $88 \%$. In addition to an enumerator, a medical staff (a doctor, a nurse, or a medical school student) participated in each interview and performed a health examination in the elder's home (Zeng, Vaupel, Xiao, Zhang, \& Liu, 2002). The first follow-up was con- 
ducted in 2000 . This study investigates the survival of the original sample between 1998 and 2000.

Nonresponses because of frailty of the oldest old pose a serious challenge to data collection. There is a consensus among researchers that proxy reporters must be used to address this issue (Rodgers \& Herzog, 1992). Thirty-two percent of the CLHLS interviews involved proxy reporters, more than $90 \%$ of whom were family members. They helped answer at least one question when the elderly respondent had difficulty participating. Only the elderly respondent, however, was permitted to answer questions regarding self-assessment and cognitive capabilities. This instruction was based on established findings that proxies are a reliable source for factual information, such as personal and family history and financial and physical health status, but not for subjective assessment and cognitive performance (Rodgers \& Herzog, 1992).

For various reasons, 894 elderly $(9.8 \%)$ in the original sample were not reinterviewed in the follow-up. Most of them were living in urban areas where housing construction has been rapidly expanding, and many residents relocated within the 2-year period. Zeng and his associates (2002) showed that age reporting of the Chinese oldest old in the survey was generally reliable up to the age of 105 . Following their practice, this analysis only included those aged between 80 and 105 . further reducing the sample size to 7,938. Data on at least one variable were missing for 1,051 cases. To maintain the sample size, we employed a random computation method to fill in these missing values. We first created computer-generated random numbers from a uniform probability distribution, then fit these random numbers into the distributions of each variable based on all the known cases and finally assigned a corresponding category of a variable to each missing value. We also generated values for missing variables with the mean or the modal category. The results remained largely the same. ${ }^{1}$

\section{MEASURES}

The dependent variable was the duration of survival in months from the baseline interview in 1998 to the first follow-up in 2000 . The values of all the independent variables were taken from the baseline interview in 1998. 
Customary activities were categorized as solitary-active, solitarysedentary, and social activities, with each type consisting of two specific activities. Solitary-active activities were composed of doing housework and gardening. Solitary-sedentary activities consisted of reading newspapers or books and watching TV or listening to the radio. Social activities included playing cards or mahjong and attending religious activities. Each specific activity was indexed at three levels: $0=$ never, 1 = sometimes, $2=$ almost every $d a y$. A score for each type of activity was created by summing the indexes of the two activities within each category, ranging from 0 to 4 , with a higher score suggesting a higher level of involvement in each type of activity.

To test whether customary activities have any independent effect on mortality, performing physical exercise was included as a control variable. In the survey, the elderly were asked if they regularly performed physical exercise. No was coded as 0 and yes was coded as 1.

Physical health status was measured by activities of daily living (ADL), physical performance, the experience of serious illness, and self-rated health. There were six questions regarding ADL in the survey: bathing, dressing, using the toilet, transferring, eating, and continence; each of which was indexed at three levels: $0=$ needed a lot of assistance, $1=$ needed some assistance, 2 = needed no assistance. $\mathrm{A}$ summed $A D L$ score ranges from 0 to 12 , with a higher score suggesting a lower level of dependence on assistance. As an objective measure of functional status, physical performance consisted of three indicators (Zeng \& Vaupe1, 2002); standing up from a chair, picking up a book from the floor, and counting the steps needed to turn around 360 degrees. Each of the three tasks was coded into three levels: $0=$ unable to perform, 1 = able with some assistance, 2 = able without assistance. ${ }^{2}$ A physical performance score was created by summing these three measures, ranging from 0 to 6 , with a higher score suggesting a higher level of physical performance. The number of times the elder suffered from serious illnesses that required hospitalization or caused the elder to be bedridden in the past 2 years were asked in the survey. Because about $90 \%$ of the sample reported none, $6 \%$ reported a frequency between 1 and 10 , and $4 \%$ reported having been bedridden all year long, this variable was coded as a dummy variable: $0=$ no serious illness, 1 = at least one serious illness. Self-rated health was measured by the question, "How do you rate your health at present?" 
and was indexed in five levels: $0=$ very $b a d, 1=b a d, 2=$ so-so, $3=$ good, 4 = very good.

Cognitive status was measured by the Chinese version of the MiniMental State Examination (Zeng \& Vaupe1, 2002), which is composed of 24 questions falling into five categories: orientation, registration, attention and calculation, recall, and language. For example, within the category of orientation, questions included, "what time of day is it right now (morning, aftemoon, evening)?" and "what is the animal year of this year?" The answer to each question was coded as 0 for wrong, 1 for correct. ${ }^{4}$ A cognitive index was constructed by summing the scores of all 24 questions and ranged from 0 to 24 , with a higher score suggesting a higher level of cognitive performance.

Previous research has shown that not only current smoking but also past smoking has a detrimental effect on health (Berkman et al, 1983). Thus, smoking was coded into three categories: never smoked, currently smokes, and smoked in the past. In the same study, Berkman et al. (1983) also found that for most age and sex groups, moderate drinkers had a lower mortality rate than abstainers, light drinkers, or heavy drinkers. Because the effect of alcohol consumption may not be linear, a series of dummy variables were created with nondrinker as the reference category. The other three categories were on average, 1 liang ( 50 grams) per day; 2 liang per day; 3 liang or more per day.

Of the sociodemographic variables, age was measured as actual age in years in 1998. Gender was coded as a dichotomous variable $(0=$ female, $1=$ male). Because $72 \%$ of the elderly in this sample were without any schooling, educational attainment was categorized as a dichotomous variable $(0=$ no schooling, $1=$ some schooling $)$. Urbanicity was coded as a dichotomous variable $(0=u r b a n, 1=r u r a l)$. Marital status was also coded as a dichotomous variable $(0=$ not married, $1=$ married). The living arrangements were coded into four categories: living alone (reference category), living with spouse only in the community, living with other relatives in the community, and living in a nursing home.

\section{STATISTICAL METHODS}

This study adopted a Weibull hazard model to examine the mortality of these elderly within the 2-year interval. A statistical test sug- 
gests a valid fit of the Weibull distribution. ${ }^{5}$ To address the research questions laid out above, a series of nested models were fitted sequentially (Lennartsson \& Silverstein, 2001; Liang et al., 2000). The first model examined the marginal relationship between customary activities, including both social and solitary, without controlling for any other factors. The second model added age, gender, physical exercise, physical status variables, and cognitive functioning status to investigate whether the effects of customary activities remained independent of physical exercise and health status. The third model added health behavior variables and other sociodemographic characteristics. The last model added the interaction effect of age and social activities to test whether the favorable effect of social activities diminished with age.

Results

Table 1 shows that $41 \%$ of this sample died in the 2-year period. About $25 \%$ of the elderly were involved in at least one kind of social activities at baseline; $44.4 \%$ participated in at least one kind of solitaryactive activity, and $51.6 \%$ were engaged in at least one kind of solitary-sedentary activity. Females accounted for three fifths of the sample. The majority of the elderly lived in rural areas $(65 \%)$ and had little schooling. Other descriptive information is also presented in Table 1 . Table 2 shows that the average age of this study sample was 92.3 with a standard deviation of 7.4 years. The average duration of survival was 20.9 months with a standard deviation of 7.9 months. A separate analysis shows that on average, the participants who died during the course of the study lived 13.3 months after they were first interviewed in 1998. The means and standard deviations of other continuous variables are also presented in Table 2.

Results of the Weibull hazard models are presented in Table 3. The first model shows that all three types of customary activities are significantly associated with lower level of mortality without controlling for any other characteristics. Contrary to the expectation, social activities appeared beneficial in this model: The hazard of death for those engaging in social activities is $85.6 \%$ of that for those who did not. 
Table 1

Frequency Distribution of Categorical Variables $(\mathrm{N}=7,938)$

\begin{tabular}{|c|c|}
\hline Variable & Frequency (\%) \\
\hline \multicolumn{2}{|l|}{ Survival status } \\
\hline Dead & 40.90 \\
\hline Alive & 59.10 \\
\hline \multicolumn{2}{|l|}{ Social activities } \\
\hline Any involvement & 25.43 \\
\hline No involvement & 74.57 \\
\hline \multicolumn{2}{|l|}{ Solitary-active activities } \\
\hline Any involvement & 44.36 \\
\hline No involvernent & 55.64 \\
\hline \multicolumn{2}{|l|}{ Solitary-sedentary Activities } \\
\hline Any involvement & 51.56 \\
\hline No involvement & 48.44 \\
\hline \multicolumn{2}{|l|}{ Gender } \\
\hline Male & 39.96 \\
\hline Female & 60.04 \\
\hline \multicolumn{2}{|l|}{ Education } \\
\hline No formal schooling & 72.16 \\
\hline Some schooling & 27.84 \\
\hline \multicolumn{2}{|l|}{ Urbanicity } \\
\hline Urban & 35.47 \\
\hline Rural & 64.53 \\
\hline \multicolumn{2}{|l|}{ Marital status } \\
\hline Married & 15.76 \\
\hline Not married & 84.24 \\
\hline \multicolumn{2}{|l|}{ Living arrangement:s } \\
\hline Living alone & 9.89 \\
\hline Living with spouse only & 7.21 \\
\hline Living with other relatives & 78.16 \\
\hline Living in a nursing home & 4.75 \\
\hline \multicolumn{2}{|l|}{ Serious illness } \\
\hline None & 89.77 \\
\hline One or more & 10.23 \\
\hline \multicolumn{2}{|l|}{ Smoking } \\
\hline Never smoked & 67.76 \\
\hline Cumently smokes & 17.36 \\
\hline Smoked in the past & 14.88 \\
\hline \multicolumn{2}{|l|}{ Drinking } \\
\hline None & 76.00 \\
\hline One liang & 10.33 \\
\hline Two liang & 5.90 \\
\hline Three liang & 7.77 \\
\hline \multicolumn{2}{|l|}{ Physical exercise } \\
\hline Yes & 26.05 \\
\hline No & 73.95 \\
\hline
\end{tabular}


Table 2

Means and Standam Deviations of Continuous Variables $(\mathrm{N}=7,938)$

\begin{tabular}{lrr}
\hline Variables & M & SD \\
\hline Duration of survival & & \\
Age & 20.91 & 7.93 \\
Activities of daily living & 92.27 & 7.37 \\
Physical performance & 10.48 & 2.69 \\
Self-rated health & 4.34 & 1.95 \\
Cognitive status & 2.61 & .83 \\
\hline
\end{tabular}

Solitary-active and solitary-sedentary activities reduced the hazard of death by $35.0 \%$ and $19.0 \%$, respectively.

In Model 2, where age, gender, physical exercise, physical status, and cognitive conditions were entered, the effect of social activities becomes insignificant. The effects of solitary-active and solitary-sedentary activities are weakened but are still highly significant. As expected, age is associated with higher likelihood of death, and men are more likely to die at an earlier age than women do. Those who performed physical exercise on a regular basis had a $23.0 \%$ lower hazard rate than those who did not. Most of the health status measures, except the presence of serious illness, are highly significant. The results show independent effects of solitary-active and solitary-sedentary activities even when physical exercise and health status are taken into account.

Other sociodemographic and health behavior variables are added in Mode1 3. The effects of customary activities as well as of other variables remained unchanged. Of the newly added sociodemographic characteristics, neither education nor urbanicity was related to mortality. Married elderly had a lower level of mortality than those who are not married and especially those who are widowed. There is no significant difference in mortality between those living alone, living with the spouse only, or living with other relatives. However, compared to living alone, living in a nursing home is associated with a $27.9 \%$ lower death hazard rate. Both current and past smoking had detrimental effects on survival. The effects of drinking alcohol are not significant.

To address the second research objective-whether the beneficial effect of social activities diminishes with age - the interaction effect between age and social activities was added in Model 4. An interest- 


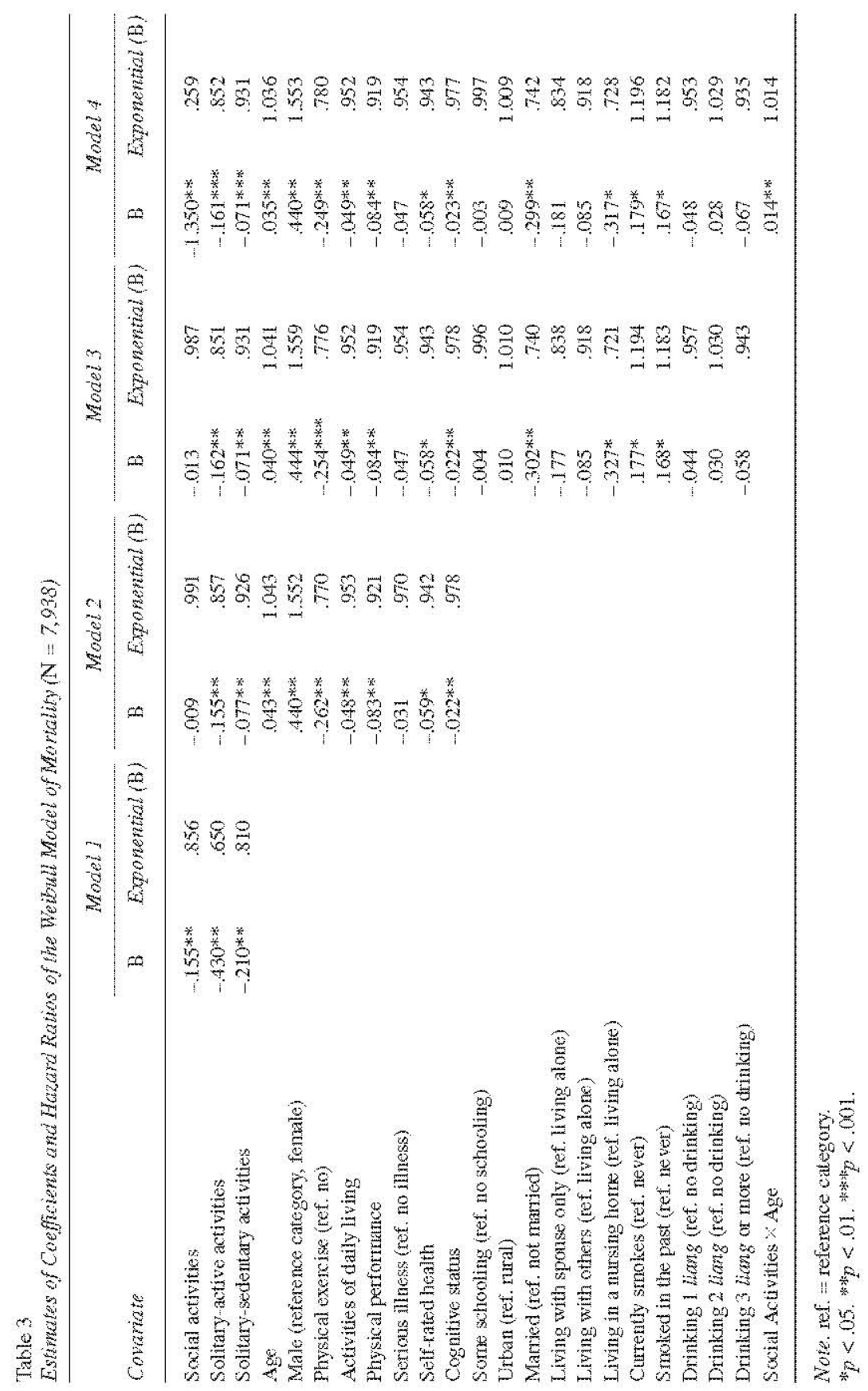

48 
ing pattern emerged regarding the effect of social activities: Although the main effect is negatively related to the hazard of death $(-1.350)$, which suggests that social activities reduce death hazard, there is a positive interaction effect with age (.014), which indicates that the beneficial effect of social activities is gradually eroded as age increases, as illustrated in Figure 1 . The line in the middle marked with 0 represents no effect on death hazard. Any values below the 0 line suggest a negative effect on death hazard - that is, a reduction in death hazard. Any values above the 0 line suggest a positive effect on death hazardthat is, an increase in death hazard. At younger ages, the effect is far below 0 , suggesting that social activities substantially reduce death hazard. But the effect approaches 0 as age increases. For example, although social activities reduced death hazard by .21 at age of 80 , they reduced it only .07 at age of 90 . Their effect reached 0 at about age 95 and steadily increased to larger positive values thereafter. This indicates that after age 95, social activities are associated with higher rather than lower, hazard of death.

In Model 4, the effects of other variables remain largely constant. Various other interaction effects were also explored, such as interactions of other customary activities with age, customary activities with gender, education, and engaging in physical exercise. None of them was found to be significant.

\section{Discussion}

Using a national sample of the elderly 80 years of age and older in select areas in China, this study investigated the relationship of customary activities (i.e., social and solitary) to mortality at very old ages. Solitary-active activities were found to be significantly associated with lower level of mortality independent of physical exercise, health status, and other sociodemographic characteristics. This finding is consistent with other studies that were reviewed in the Research Objectives section (Glass et al., 1999; Lennartsson \& Silverstein, 2001; K. Morgan \& Clarke, 1997). Solitary-sedentary activities, which do not involve much physical mobility, were also found to be significant even after other characteristics were taken into account. Consistent with what was found by Glass and colleagues (1999), cus- 


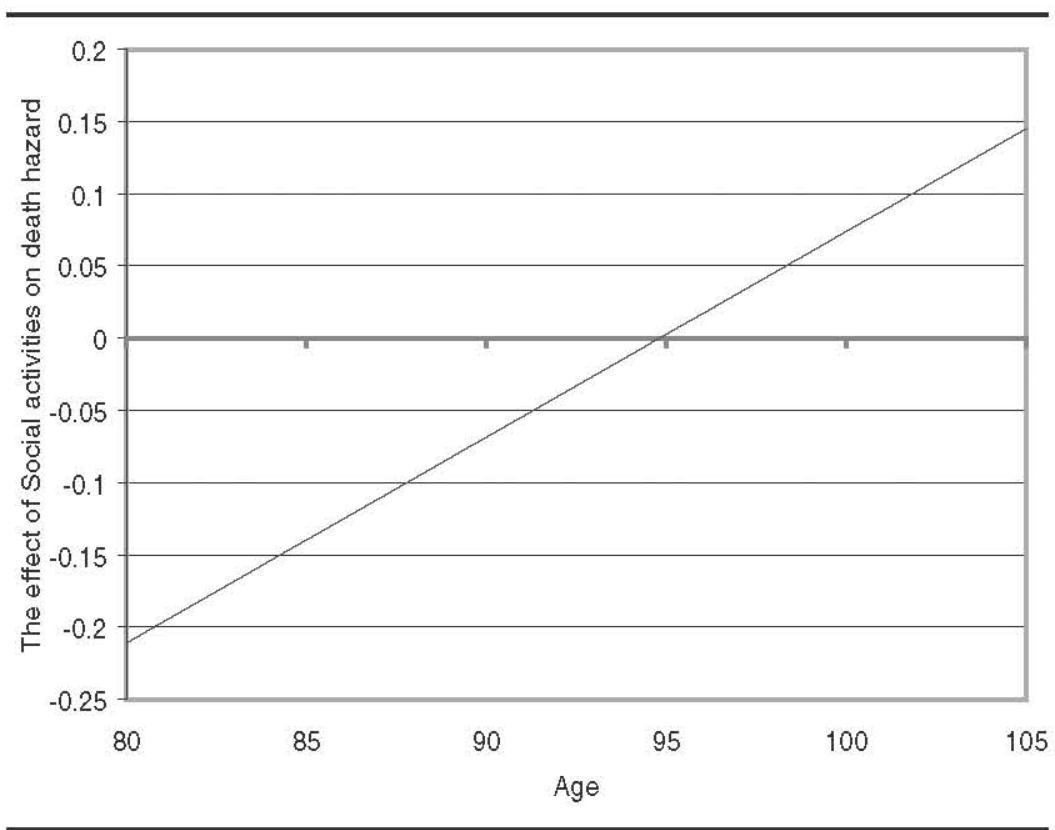

Figure 1. The effect of social activities on death hazard by age.

tomary activities, which are not as physically intensive as fitness activities, seem to have independent effects on the elderly's survival at very old ages.

This study also demonstrates the importance of differentiating between various kinds of customary activities, especially along the social versus solitary dimension. An age-related, downward trend of the beneficial effect of social activities on survival was documented. At very old ages, the favorable effect of social activities was reversed. This finding seems to suggest benefits of social withdrawal at very old ages. Such a theme was discussed in more depth in their study of the elderly aged 85 or above in San Francisco, where Johnson and Barer (1997) observed that individuals were active agents, continuously readapting themselves to new challenges in late life. They described physical disability as an increasing constraint. To cope with it, the very old withdrew selectively from social relationships, simplifying and narrowing the boundaries of their social world. The elderly in their study deliberately reduced their social roles and only retained 
those relationships that they saw as necessary. They did not view retreating from social relations as a passive response to their physical status. Rather, they regarded such disengagement as a positive change. They attached significant meaning to mundane, commonplace activities, such as preparing meals and listening to the radio. Our results are consistent with Johnson and Barer suggesting that the elderly tend to withdraw from social activities at very old ages, which appears to be beneficial to survival.

So far, most of the research regarding mortality of the oldest old has been limited to Western populations. In this study, we used the CLHLS, which, to our knowledge, is the first large-scale survey of the oldest old in a developing country, to test some existing theories and findings in a different cultural and social setting. Because the Chinese survey provided detailed information on the elderly's health status, fitness activities, and other characteristics, we could assess the independent effects of customary activities on mortality when controlling for other factors. This analysis also empirically tested the interaction effect of age and engaging in social activities based on large survey data, which has not been documented in the literature.

Caution is warranted in generalizing the findings of this study. First, the 2-year follow-up period is short. Because the participants of the study were 80 years of age and older, an age at which rapid changes in health and death are common, the results could be biased by focusing on a 2-year period of this ongoing process. For instance, the effect of cognitive status could be underestimated if some elderly experienced sudden, intellectual decline but were alive at the time of the follow-up, then died shortly afterwards, a phenomenon termed as terminal drop (Belsky, 1990). Therefore, a longer period of observation would be desirable. Second, because of the limitation of the data, only two kinds of social activities were included: playing cards or mahjong and attending religious activities. Other forms of social activities, such as visiting friends and participating in other organizations, were missing. Finally, reductions in social activities or social contacts are not necessarily equivalent to exclusion from the social world. Lang and Carstensen's (1994) study showed that reductions in social contacts at very old ages were mainly limited to social relationships that were not close, whereas very close relationships within the elderly's inner circles remained largely intact. Emotional ties with 
others were maintained but became increasingly exclusive, with more focused social partners, such as family members. Therefore, withdrawal from some social relationships may represent an intentional selective process in which the elderly invest increasingly limited resources, such as health and energy, in a select few to maintain a necessary level of social engagement (Carstensen, 1992). This study partially tapped external aspects of social engagement, whether the elderly were engaged in certain types of social activities, whereas internal qualities (e.g., emotional support, closeness, feelings of social embeddedness, and so forth) were not addressed. Hence, it is premature to conclude that social disengagement, rather than social engagement, is beneficial to the survival of the elderly at very old ages. Studies that include a fuller range of social engagements are needed to assess more fully their impacts.

Nevertheless, the findings of the beneficial effects of solitary activities on the one hand, and the decrease in favorable effects of social activities on the other, do suggest that more attention be devoted to understanding the unique characteristics of the elderly at very advanced ages, when they are increasingly physically and mentally restricted. Withdrawing from a bustling world and limiting oneself to a narrow environment may be an adaptive response at such ages. Psychosocial risk factors that directly affect health outcomes, such as physical exercise and social activities, are widely recognized in the literature (House, Kessler, \& Herzog, 1990; Link \& Phelan, 2000). The findings of this study seem to suggest that the effects of these risk factors may change with chronological age. It is important to recognize and understand the distinctive needs of and challenges faced by the oldest old population - one of the fastest growing age groups in the world. Any intervention measures should be congruent with such uniqueness.

\section{NOTES}

1. A separate analysis with all the participants with missing values deleted showed similar re sults as well.

2. The answer to the third question ranges from 2 steps to 72 steps, and 2,072 participants were coded as "unable to perform." Based on its distribution, this variable was categorized into three levels: $1=$ unable to perform, $2=$ more than 10 steps, $3=$ within 10 steps. 
3. Although there were questions that asked the respondent about certain diseases, including hypertension, diabetes, cataract, and cancer, it is quite likely that many diseases were not diagnosed among the elderly in rural areas where access to medical care was more limited than in urban areas. Therefore, this information was not included.

4. There was one exception. One of the questions asked the respondent to name as many kinds of food as possible in $1 \mathrm{~min}$. To be consistent with the format of the answers to oher questions, based on the frequency distribution, the answer was coded " $O$ " for those who gave three or fewer names and "1" for those who gave more than three names.

5 . The fact that the plot of $\log (-\log [S])$ versus $\log (t)$ is roughly a straight line in which $S$ refers to the probability of survival and treters to survival duration, suggests that adopting a Weibull distribution is a reasonable choice (Lee, 1992).

\section{REFERENCES}

Anderson, B. A., Kim, C. S., Romani, J. H., Traphagan, J. W, \& Lin, J. (1999), Living arrangements and mortality risks of the urban elderly in Yunnan Province, China, 1995 (Report, No. 99-435). Ann Arbor: University of Michigan, Population Studies Center.

Anstey, K. J., Luszcz, M. A., \& Giles, L. C. (2001). Demographic, health, cognitive, and sensory variables as predictors of mortality in very old adults. Psychology and Aging, 16, 3-11.

Belloc, N. B. (1973). Relationship of health practices and mortality. Prevenive Medicine, 2, 67 . 81.

Belsky, J. K. (1990). The psychology of aging: Theory, research, \& interventions (2nd ed.). Pacific Grove, CA: Brooks/Cole.

Berkman, L. F., \& Breslow, L. (1983). Social networks and mortality risk. In L. F. Berkman \& L. Breslow (Eds.), Healh and ways of living (pp. 113 160). New York: Oxford University Press.

Berkman, L. F., Breslow, L., \& Wingard, D. (1983). Health practices and mortality risk. In L. F. Berkman \& L. Breslow (Eds), Healh and ways of living (pp. 61-112). New York: Oxford University Press.

Berkman, L. F., Glass, T., Brissete, I., \& Seeman, T. E. (2000). From social integration to health: Durkheim in the new millennium. Social Science \& Medicine, $51,843-857$.

Bygren, L. O. Konlann, B. B., \& Johansson, S. (1996). Attendance at cultural events, reading books or periodicals, and making music or singing in a choir as determinants for survival: Swedish interview survey of living conditions. British Medical Joumal, 313, 1577-1580.

Carstensen, L. L. (1991). Selectivity theory: Social activity in life-span context. Anmual Review of Gerontology and Geratrics, 11, 195-217.

Carstensen, L. L. (1992). Social and emotional patterns in adulthood: Support for socioenotional selectivity theory. Psychology and Aging, 7, 331-338.

Cerhan, J. R., Chiu, C., Wallace, R. P., Lemke, J. H., Lynch, C. F., Torner, J. C., et al. (1998). Physical activity, physical function, and the risk of breast cancer in a prospective study among elderly women. Joumal of Gerontology, 53, M251-256.

Cornman, J.C., Goldman, N., Glei, D. A., Weinstein, M., \& Chang, M.C. (2003). Social ties and perceived support: Two dimensions of social relationships and health among the elderly in Tawan. Joumal of Aging and Health, 15, 616-644.

Cumming, E., \& Henry, W. E. (1961). Growing old: The process of disengagement. New York: Basic Books. 
DiPietro, L. (2001). Physical activity in aging: Changes in patterns and their relationship to health and functions [Special issue]. Jountals of Gerontology, 564, 13-22.

Glass, T. A.. Mendes de Leon, C., Marottoli, R. A., \& Berkman, L. F. (1999). Population based study of social and productive activities as predictors of survival among elderly Americans. British Medical Joumal, 319, 478-483.

Ho, S. C. (1991). Healh and social predictors of mortality in an elderly Chinese cohort. American Joumal of Epidemiology, $133,907-921$.

House, J. S., Kessler, R. C., \& Herzog, A. R. (1990). Age, swiceconomic status, and health. Milbank Quarterly, 68, 383-411.

Johnson, C. L., \& Barer, B. M. (1992). Pattems of engagement and disengagement among the oldest old. Joumal of Aging Studies, 6, 351-364.

Johnson, C. L., \& Barer, B. M. (1997). Life beyond 85 years. New York: Springer:

Kaplan, G. A. (1992). Heath and aging in the Alameda County study. In K. W. Schaie, D. Blazer, \& J. S. House (Eds.), Aging, health behaviors, and health outcomes (pp. 69-88). Hillsdale, NI: Lawrence Erlbaum Associates.

Kaplan, G. A., Hann, M. N., Syme, S. L, Minkler, M., \& Windeby, M. (1987). Socioconomic status and health. In R. W. Amler \& H. B. Dull (Eds.), Closing the gap: The burden of unneessary illness (pp. 125-129). New York: Oxford University Press.

Kaplan, G. A., Seeman, T. E., Cohen, R. D., Knudsen, L. P., \& Guralnik, J. (1987). Mortality among the elderly in the Alameda County study: Behavioral and demographic risk factors. American Joumal of Public Health, 77, 307-312.

Korten, A. E., Jorm, A. F., Jiao, Z., Letenneur, L., Jacomb, P. A., Henderson, A. S., et al. (1999) Health, cognitive, and psychosocial factors as predictors of mortality in an elderly community sample. Joumal of Epidemiology and Community Health, 53, $83-88$.

Lang, F. R., \& Carstensen, L. L. (1994), Close emotional relationships in later life: Further support for proactive aging in the social domain. Psychology and Aging, 9, 315-324.

Lee, E. T.(1992). Statisticalmethods for survival data anahysis. New York: John Wiley \& Sons.

Lennartsson, C., \& Silverstein, M. (2001). Does engagement with life enhance survival of elderly people in Sweden? The role of social and leisure activities. Joumal of Gerontology; $56 B, 335-342$

Liang, J., McCarthy, J. F., Jain, A., Krause, N., Bennett, J. M., \& Gu, S. (2000). Sociceconomic gradient in old age mortality in Wuhan, China. Journal of Gerontology, 57B, S222-S233.

Link, B. G., \& Phelan, J. C. (2000). Evaluating the fundamental cause explanation for social disparities in heath. In C. E. Bird, P. Conrad, \& A. M. Fremont (Eds.), Hondbook of medical sociology (pp. 33-46). Upper Saddle River, NI: Prentice Hall.

Liu, X, Hermalin, A. I., \& Chuang, Y. L. (1998). The effects of education on montality among older Taiwanese and its pathways. Joumal of Gerontology, 53B, S71-82.

Morgan, D. L. (1988). Age differences in social network participation. Journal of Gerontology, 43, $5129-137$.

Morgan, K., \& Clarke, D. (1997). Customary physical activity and survival in later life: A study in Nottingham, UK. Joumal of Epidemiology and Community Health, 5I, 490-493.

Morgan, K., Dallosso, H. Bassey, E. J., Ebrahim, S., Fenten, P. H., \& Arie, T. H. D. (1991). Customary physical activity, psychological well-being and successful aging. Ageing and Society, 11, 399-415.

Parker, M. G., Thorslund, M., \& Nordstrom, M. (1992). Predictors of mortality for the oldest old. A 4-year follow-up for community-based elderly in Sweden. Archives of Gerontology and Geriatrics, 14, 227-237. 
Rodgers, W.L., \& Herzog, A. R. (1992). Collecting data about the oldest old: Problems and procedures. In R. M. Suzman. D. P. Willis, \& K.G. Manton (Eds), The oldest old, (pp. 135-156). New York: Oxford Univenity Press.

Rowe, J. W., \& Kahn, R. L. (1998). Stuccessfit aging. New York: Pantheon.

Sabin, E.P. (1993). Social relationships and mortality among the elderly. The Toumal of Applied Gerontology, 12, 44-60.

Suzman, R. M., Manton, K. G., \& Willis, D. P. (1992). Introducing the oldest old. In R. M. Suzman, D. P. Willis, \& K. G. Manton (Eds.), The oldest old (pp. 3-14). New York: Oxford University Press.

United Nations. (2001). Workt population ageing: 1950-2050. New York: United Nations, Department of Economic and Social Affairs, Population Division.

Welin, L., Larsson, B., Svardsudd, K., Tibblin, B., \& Tibblin, G. (1992). Social network and activities relation to mortality from cardiovascular diseases, cancer and other causes: A 12 year follow up of the st udy of men bonin 1913 and 1923. Joumal of Epidemiologyand Comminity Health, 46, 127-132.

Yu, E. S. H., Kean, Y. M., Slymen, D. J., Lin, W. T., Zhang, M., \& Katzman, R. (1998). Selfperceived health and 5-year mortality risks among the eldedy in Shanghai, China. American Journal of Epidemiology, 147, 880-890.

Zeng, Y., \& Vaupel, J. W. (2002). Functional capacity and self-evaluation of health and life of oldest old in China. Joumal of Social Issies, 58, 733748.

Zeng, Y., Vaupel, J. W., Xiao, Z., Zhang, C., \&.Liu, Y. (2002). Sociodemographic and health profiles of the oldest old in China. Fopulation and Development Review, 28, 251-273.

Zunzunegui, M., Alvarado, B. E., Ser, T. D., \& Otero, A. (2003). Social networks, social integration, and social engagement determine cognitive decline in community-dwelling Spanish older adults. Joumal of Gerontology, 58B, $593-100$. 